\title{
Uso da tecnologia interativa e a experimentação no ensino de Química
}

\author{
Antonio Leonilde de Oliveira*;(Mestrando em Ensino do Programa de Pós-graduação em Ensino - \\ PPGE - CAMEAM/UERN) \\ José Clovis Pereira de Oliveira; (Mestrando em Ensino do Programa de Pós-graduação em Ensino - \\ PPGE - CAMEAM/UERN) \\ Email*: leonildesitau@gmail.com
}

Resumo:

O presente artigo trata-se da análise de uma prática experimental utilizada no ensino de química, mediada pelo uso da tecnologia interativa, realizada com alunos da $3^{\mathrm{a}}$ série do ensino médio da Escola Estadual Francisco de Assis Pinheiro no município de Itaú no estado do Rio Grande do Norte. Para o estudo foram selecionados aleatoriamente 16 alunos para responderem a um questionário com questões objetivas e abertas a fim da análise do estudo - a experimentação com uso das tecnologias interativas pode propiciar uma significância maior ao ensino. Para isso foram divididos em dois grupos, numerados por 1 e 2, onde o grupo 1 participou de toda a pesquisa e o grupo 2, apenas da experimentação, ou seja, não houve a mediação da tecnologia interativa. De forma, que o estudo em questão, suscita aos professores de química atentar para essa proposta metodológica uma vez que, $100 \%$ (cem por cento) dos alunos confirmaram que a experimentação mediada pelo uso das tecnologias interativas facilita o processo de ensino- aprendizagem e acrescenta significado a prática docente. Portanto, o estudo em tela servirá para os profissionais licenciados em química atentar e refletir sobre sua prática pedagógica.

Palavras chaves: experimentação; tecnologia interativa; mediação; prática docente.

\begin{abstract}
:
This article comes from the analysis of an experimental practice used in chemistry teaching, mediated by the use of interactive technology, held with students of the 3rd year of high school Estadual Francisco de Assis Pinheiro in Itaú municipality in the state of Rio Grande do Norte. For the study were randomly selected 16 students to answer a questionnaire with objective questions and the open end of study analysis - experimentation with use of interactive technologies can provide greater significance to education. To this were divided into two groups, numbered by 1 and 2 , wherein the group 1 took part in all research and group 2, only experimentation, i.e., no mediation of interactive technology. So that the study in question gives rise to chemistry teachers pay attention to this methodological proposal since $100 \%$ (one hundred percent) of the students confirmed that the trial mediated by the use of interactive technologies facilitates the teaching-learning process and it adds meaning to teaching practice. Therefore, the study will screen for professional graduates in chemistry attend and reflect on teaching practice.
\end{abstract}

Key words: experimentation; interactive technology; mediation; teaching practice.

\section{Apresentação}

Partimos da premissa de que a química, como qualquer outro componente curricular, necessita do confronto da teoria estudada nos livros, à realização de atividades práticas, além da contextualização 
permanente do assunto estudado com as vivências cotidianas do aluno e, por que não dizer, da sociedade como um todo.

Foi partindo disso que encaminhamos esta pesquisa, onde a mesma visa analisar se o incremento da tecnologia interativa associada a uma experimentação química facilita a aprendizagem, no tocante à organização das ideias e sistematização do conhecimento.

Já em relação às novas tecnologias presentes na escola destaca-se que esta possui um laboratório de informática onde estão disponibilizados 15 computadores (máquinas), os quais estão em total desuso, devido à falta de manutenção. Para se ter uma idéia da gravidade, deste total, apenas três funcionam plenamente. Também, em relação às novas tecnologias, pode-se destacar que na escola existem dois projetores de imagens e uma lousa digital. Destes, os únicos que estão sendo utilizados de fato, são os projetores, que rotineiramente são revezados pelos professores.

A análise revela que nos últimos três anos, há um baixo nível de aprendizagem nas primeiras séries do ensino médio da escola, na maioria dos componentes curriculares, e mais acentuadamente nas áreas de Ciências da Natureza e Matemática. E isso tem causado efeitos negativos que vem contribuindo desfavoravelmente nos dados escolares e causando um índice acentuado de reprovação, um alto índice de evasão e a desmobilização dos alunos pelas aulas.

É nesse contexto que emerge o presente trabalho, fundamento em autores como (CAETANO, 2012); (SILVA, 2009); (SAVIANI, 2012); (RANCIÈRE, 2002); (PERRENOUD, 1995); (FERREIRA, 1998); (MASETO, 1998), os Parâmetros Curriculares Nacionais, os cadernos do PACTO e outros autores que aparecerão no decorrer da pesquisa, o presente trabalho partiu da importância do professor reflexivo, onde analisa e reflete sua prática, situando-a no processo constante de formação e compreensão da melhor forma de trabalhar o conteúdo do componente curricular de química.

Dentro desta reflexão, Thomas S. Kuhn (2005) "as crises são uma pré-condição necessária para a emergência de novas teorias". Tomando por base a enunciação proposta por Kuhn , hoje mais do que nunca é tempo de novas teorias, novas proposições e novos desafios para prática docente.

Assim, as tecnologias quando bem utilizadas, no meio educacional, ou em qualquer espaço ou instituição, trazem a capacidade de aproximação e envolvimentos dos estudantes.

Conforme descreve Masetto,

[...] tempos houve em que se pensou que a tecnologia resolveria todos os problemas da educação, e outros em que se negou totalmente qualquer validade para essa mesma tecnologia, dizendo-se ser suficiente que o professor dominasse um conteúdo e o transmitisse aos alunos, hoje, encontramos em uma situação que defende a necessidade de sermos eficientes e queremos que nossos objetivos sejam atingidos da forma mais completa e adequada possível, e para isso, não podemos abrir mão da ajuda de uma tecnologia pertinente (MASETTO, 1998).

E, segundo Moran,

A concepção de ensino e aprendizagem revela-se na prática de sala de aula e na forma como professores e alunos utilizam os recursos tecnológicos disponíveis. A presença dos recursos tecnológicos na sala de aula não garante mudanças na forma de ensinar e aprender. A tecnologia deve servir para enriquecer o ambiente educacional, propiciando a construção de conhecimentos por meio de uma atuação ativa, crítica e criativa por parte de alunos e professores (MORAN, 1995; apud MAINART: SANTOS, 2010).

Diante deste contexto surge essa pesquisa, que visa analisar se a experimentação química (aula prática), com o auxílio da tecnologia interativa (gravação de vídeo, exibição e postagem nas redes sociais) facilita o processo de ensino aprendizagem. A pesquisa foi organizada através do diagnóstico da Escola, aula teórica abordando um determinado assunto de química e o seu confronto com a prática, onde essa experimentação foi mediada com a gravação do experimento, exibição da prática executada pelos alunos, finalmente, a postagem do vídeo na internet, e, fundamentada nos autores explicitado anteriormente.

Para o estudo foram selecionados aleatoriamente 16 alunos, divididos em dois grupos (1 e 2), para responderem a um questionário com questões objetivas e abertas, a fim da análise do estudo - a experimentação, com uso das tecnologias interativas propiciam uma significância no ensino. 


\section{A tecnologia interativa e as práticas educativas}

Entende-se por tecnologia interativa, todo dispositivo, seja ele físico ou em rede, que possibilita a interação entre as pessoas, e deste com as mesmas e, neste caso, em especial, a tecnologia inserida às práticas pedagógicas presentes na escola.

Nesta perspectiva, não temos aqui a intenção de elencar todas as possibilidades e nem tão pouco discorrer nas várias práticas educativas existentes e disponibilizadas ao ensino, mas sim ao nosso estudo, que são as práticas educativas no ensino de química.

Assim, busca-se fazer uma relação entre a tecnologia interativa e as práticas educativas partindo da concepção de contextualização, que surgiu com a reforma do ensino médio, a partir da Lei de Diretrizes e Bases da Educação - LDB, que orienta a compreensão dos conhecimentos para uso cotidiano. E que teve origem nas diretrizes curriculares postas nos Parâmetros Curriculares Nacionais (PCNs), os quais visam um ensino de química centrado na interface entre informação científica e contexto social.

Neste contexto surge uma nova abordagem metodológica, uma vez que, trabalhar com momentos pedagógicos dessa natureza, como é esta pesquisa, tem-se a compreensão que as práticas pedagógicas executadas na escola, fundamentam-se numa perspectiva tradicional de educação que vem permeando a maioria das instituições escolares do país até os dias atuais.

Nesta concepção tradicional da prática pedagógica, o professor ocupa o centro do processo de ensino, uma vez que é ele o responsável por escolher conteúdos a serem transmitidos, planejar o trabalho pedagógico tendo em vista a transmissão de conteúdos acumulados pela humanidade, conforme informação retirada do caderno III, etapa II do Pacto - Brasil (2014, p. 17).

Assim, não nos reportaremos nesta perspectiva, pois trabalhar com os estudantes ocupando a centralidade do processo, conforme aponta as Diretrizes Curriculares Nacionais do Ensino Médio DCNEM, os jovens passam a ser posicionados como sujeitos centrais do processo educativo e, portanto, portadores de direito, transpondo o papel de professor de transmissor para mediador do conhecimento.

Assim sendo, não convém ampliar o debate e instigar as práticas educativas ditas tradicionais, já que não é nosso objeto de estudo. De forma que partiremos da necessidade de repensarmos as práticas pedagógicas vivenciadas atualmente nas instituições escolares e ao mesmo tempo a inserção nas mesmas, das novas tecnologias.

Com este intuito, o planejamento de ensino e o material didático selecionado devem contemplar, as conexões entre os aspectos das Ciências da Natureza - vista como uma criação humana, delimitada por uma perspectiva sócio-histórica, com o objetivo de conhecer o mundo natural - com aspectos da tecnologia - definida como o mundo construído artificialmente pelo homem a partir do conhecimento científico estabelecido com o objetivo de atender suas necessidades, no caso a sociedade. Conforme aponta o caderno III de Ciências da Natureza do Pacto Nacional para o Ensino Médio (Brasil, 2014, p. 24).

Corroborando com o que foi anunciado anteriormente, no estudo Integração da Tecnologia da Informação do MEC, os organizadores citam Silva (2005, p. 64), que diz que a educação do cidadão não pode estar alheia ao nosso contexto socioeconômico-tecnológico, cuja característica geral não está mais na centralidade da produção fabril ou na mídia de massa, mas na informação digitalizada como nova infra-estrutura básica, como novo modo de produção.

Tomando por base essa nova conjuntura, a qual a sociedade estar inserida, cabe ao professor organizar e sistematizar sua prática docente, de forma a ter o computador, o celular ou outro dispositivo eletrônico, bem como a internet, como fonte de ambiência informacional, que pode auxiliálo dentro desta nova lógica comunicacional. É essa relação que buscamos fazer nesta pesquisa, o uso das tecnologias interativas na mediação das práticas pedagógicas - através da experimentação.

\subsection{A escola e a tecnologia}

O ponto de partida para nossa discussão entre escola e tecnologia tem por base a questão educacional do ponto de vista de que é a Educação que congrega a ação formadora do ser humano, e ela acontece através da sistematização do conhecimento na instituição denominada Escola. 
Para Rodrigues (2001, p. 234), os atributos do ato educativo como o de preparar os indivíduos para a vida social, institui-se um parâmetro universal sobre os fins da educação. Desta forma, coloca a escola como meio para que se alcance o ato educativo e é, através dela, que outro discurso aparece e aos atributos do ato educativo deseja ser alcançado, que é o de formar os indivíduos para o exercício da cidadania.

Já o Saviani (2012, p. 12), aponta que a educação é um fenômeno próprio dos seres humanos e ela é uma exigência do e para o trabalho, bem como ela própria é um processo de trabalho. E trata-se de um trabalho não material, pois trata-se da produção de idéias, conceitos, valores, símbolos, hábitos, atitudes e habilidades. Por que não dizer da produção do saber, sobre: a natureza, a cultura, isto é, o conjunto da produção humana.

A Escola hoje exige de todos os seus alunos muito mais que competências elementares. Afirma Perrenoud (1995, p. 83), é preciso aprender a exprimir-se, a raciocinar, a organizar-se, a ser autônomo, a tratar das informações, a aprender a aprender: outras tantas aquisições complexas que se estendem por longos anos e que pressupõem um interesse pessoal e a confrontação cotidiana com problemas, situações novas, com outras formas de dizer e de pensar.

Nesta perspectiva apontada por diversos autores, é que buscamos dialogar sobre a importância da mediação das tecnologias com a escola, com as práticas pedagógicas, com os professores e com os alunos. E aqui, reafirmando essa importância, nos reportamos a Rasinen (2003), julgamos que a grande vantagem de integração da tecnologia na educação é o desenvolvimento de múltiplas competências nos alunos que lhes permitam ser melhores cidadãos, não apenas ao nível da aquisição de conhecimentos escolares mas, sobretudo, na sua relação com o mundo.

É dentro desta lógica que busca fazer a relação das necessidades de integração das tecnologias à escola, pois segundo Cabero (2006), o envolvimento de tecnologias na educação torna-se necessário em consideração a alguns aspectos singulares relacionados com as suas características, as suas particularidades comunicativas e as suas possibilidades didáticas.

Devemos olhar para as tecnologias como instrumento a serviço da educação e que pode melhorar os desempenhos, aumentar a motivação dos alunos, para aprender e alcançar melhores resultados (RAMOS, 2005).

\subsection{O ensino de química e a tecnologia interativa}

De modo geral, podemos afirmar que o ensino de Química, ou da área da Ciência da Natureza vem sendo abordado a partir de uma perspectiva em que não se levam em conta as relações entre à ciência, a tecnologia, a sociedade e o ambiente (caderno III da etapa II do Pacto - Brasil, 2014, p. 22). Na Escola campo de realização da pesquisa, a realidade infelizmente não se diferencia muito deste contexto, apontado no caderno de formação dos professores do ensino médio - Pacto.

Assim sendo, cabe aos professores desta área e neste caso em especial, o de Química, atuarem de maneira a romperem com as práticas tradicionais, que não são compatíveis com a formação humana integral que as DCNEM apontam como meta desta etapa de formação.

Partimos desta reflexão para adequar o ensino de química as mudanças necessárias para o contexto de uma educação cientifica que busca promover a integração entre ciência, tecnologia e sociedade, as chamadas CTS.

Para isso, o professor de Química deve observar que o currículo tradicional não apresenta o ensinar da ciência nesta perspectiva, tornando em parte, a cerne do problema. Mas, o professor enquanto idealizador e executor da sua prática docente deve pautá-lo numa perspectiva em que o conteúdo e sua prática proporcione uma conexão e uma integração com o cotidiano do aluno.

Esta concepção vai de encontro com a proposta das DCNEM, que coloca o aluno como sujeito central no processo de ensino aprendizagem, uma vez que, associa sua compreensão pessoal de seu ambiente social, tecnológico e natural, e passa a encontrar sentido na ciência em suas experiências diárias (Caderno III, Pacto, Brasil, 2014, p. 24).

Assim sendo, necessita redefinir o papel do professor que: "mais que ensinar, trata-se de fazer aprender (....), concentrando-se na criação, na gestão e na regulação das situações de aprendizagem" (Perrenoud, 2000, p. 139), onde passa a ser o mediador que busca desenvolver as aprendizagens para e com o aluno. 
Nessa redefinição de seu papel, o professor passa a mobilizar os alunos para incentivar a investigação e a problematização do mundo a sua volta, alicerçados em temáticas do seu cotidiano, na busca da solução dos problemas, com reflexões individuais e coletivas e com estreita relação e interação com as tecnologias interativas a ele disponibilizadas.

Propomos não como forma indissolúvel e imputável para consonância com o que preza as DCNEM, o trabalho do professor com práticas docentes que envolva a experimentação como forma de minimizar o efeito adverso de um conteúdo solto e sem conexão com a realidade do aluno.

O princípio desta prática deve partir da contextualizaçãoda química, não como forma de promover uma ligação artificial, entre o conhecimento e o cotidiano do aluno. Neste caso, citando exemplos como ilustração, ao final de algum conteúdo, mas que contextualizar é propor "situações problemáticas reais e buscar o conhecimento necessário para entendê-las e procurar solucioná-las.” (PCN+, p.93).

O ensino de química deve envolver uma abordagem pedagógica-curricular problematizadora da realidade do aluno, produzindo sentidos para o estabelecimento de significados entre os conhecimentos científicos, escolares e cotidianos (caderno III da etapa II do Pacto - Brasil, 2014, p. 34).

No intuito de trabalhar nessa abordagem o professor pode e deve utilizar recursos tecnológicos, com intencionalidade educativa de modo a proporcionar situações de aprendizagens (Hennessy, Rutven\&Brindley, 2005, Ramos, 2005, Damásio, 2007, Costa, 2008; apud CAETANO, 2012).

Neste contexto Morin diz:

O uso da TIC na criação de rede de conhecimentos traz subjacente a provisoriedade e a transitoriedade do conhecimento, cujos conceitos articulador, constituem os nós dessa rede, flexível e sempre aberta a novas conexões, as quais favorecem compreender problemas globais e fundamentais para neles inserir conhecimentos parciais e locais (MORIN, 2000).

Ainda, fortalecendo o uso das TICs no ambiente escolar Almeida (2000) reforça que criar ambientes de aprendizagem com a presença da TIC significa utilizá-la para a representação, a articulação entre pensamentos, a realização de ações, o desenvolvimento de reflexões que questionam constantemente as ações e as submetem a uma avaliação contínua.

A ação docente deve contemplar a instrumentalização dos diversos recursos tecnológicos disponibilizados na escola, ou até mesmo que se encontra disponível ao aluno em locais e meios que tiver acesso. Neste movimento de inovação de sua prática o professor passa a colaborar e a cooperar para a criatividade do aluno, e tornar sua aprendizagem colaborativa, crítica e transformadora.

\section{Metodologias utilizadas}

Neste estudo foi priorizado uma maior aproximação com a realidade do caso ( a experimentação e o uso das tecnologias interativas), como prática docente no intuito de perceber sua aplicação e eficácia na melhoria do processo de ensino aprendizagem. Assim, buscou desenvolvê-la por método de pesquisa exploratória e descritiva quantitativa e qualitativa. Segundo Andrade (2006), pesquisas exploratórias são informações obtidas através de fontes bibliográficas com a finalidade de proporcionar maiores informações sobre determinado assunto, definindo objetivos ou formulando hipóteses de uma pesquisa.

Segundo Andrade (2006), Pesquisa descritiva são fatos descritos, observados, registrados, analisados sem interferência do pesquisador. O trabalho realizado baseia-se na observação dos fatos tal como ocorre na realidade. Foram utilizados questionários na escola de ensino médio no município de Itaú/RN. A pesquisa foi realizada com 16 alunos de faixa etária de 13 a 18 anos, nos meses de abril e maio do ano corrente, para avaliar até que ponto a experimentação mediada pela tecnologia interativa melhora a prática docente no ensino de química e facilita o processo de ensino aprendizagem.

Para servir de células foram escolhidos aleatoriamente 16 (dezesseis) alunos da $3^{\mathrm{a}}$ série do ensino médio para aplicarmos um questionário qualitativo, a fim de verificar a freqüência de uso e os principais equipamentos tecnológicos utilizados pelos professores das disciplinas específicas e em especial na busca do diagnóstico de como eram as aulas da disciplina de química, no tocante ao uso 
das novas tecnologias aplicadas à escola pelos professores desta área do conhecimento e a experimentação dos conteúdos explorados.

Os alunos escolhidos aleatoriamente durante essa fase foram designados por (A, B, C, D, E, F, G e H), com índice 2 para representar o grupo de alunos sem acesso a formatação da pesquisa e com índice 1 com acesso, como forma de não identificá-los. Estes responderam ao questionário que continha perguntas subjetivas e objetivas que levava a refletir sobre o seu entendimento sobre tecnologia, sobre a sua inclusão na era digital, além de buscar saber se os alunos conheciam as tecnologias disponíveis na escola, quais professores e disciplinas que mais utilizam, além de buscar saber deles a importância do uso dessas tecnologias para as aulas de química e se o uso da experimentação mediada por essas tecnologias facilitaria o processo de ensino aprendizagem.

O estudo teve início com a observação do campo da pesquisa, com o diagnóstico inicial do campo, do corpo docente e corpo discente. De posse dessas informações iniciou-se a elaboração dos questionários a ser aplicado nos dois grupos (1 e 2), para, em seguida, organizar o planejamento da aula, sistematização do experimento com a divisão dos grupos, realização do experimento com a gravação do vídeo e posteriormente a edição, exibição no auditório da escola e em seguida criação da fanpage e postagem do vídeo.

A sequência trabalhada para sistematizar o estudo ocorreu mediante nove etapas, descritas conforme segue:

- $\quad$ Aplicação de questionário semi-estruturados com os alunos do grupo 1 e 2 da nossa pesquisa;

Pesquisa exploratória utilizando os livros (grupo2) e computadores/notebook da escola com acesso a internet (grupo 1);

- Realização da aula expositiva/dialogada/reflexiva/problematizadora com os alunos dos grupos 1 e 2; dos grupos 1 e 2;

Divisão dos grupos e realização dos experimentos em dias diferentes com os alunos

- $\quad$ A experimentação com os alunos do grupo 1, com a gravação do vídeo por intermédio do celular;

- $\quad$ Exposição dos vídeos produzidos a partir da experimentação com os alunos do grupo 1 ;

- $\quad$ Postagem dos vídeos produzidos pelos alunos do grupo 1 na fanpage da escola;

- $\quad$ Aplicação de questionário igualmente estruturado com informações inerentes ao conteúdo trabalhado na aula e prática realizada com os alunos dos grupos 1 e 2;

- $\quad$ Sistematização dos resultados.

Vale ressaltar que a escolha da escola e da turma analisada nesta pesquisa ocorreu de forma intencional e todas as informações requeridas dos alunos foram tratadas com maior rigor e resguardando a origem de suas opiniões. Por isso a designação da identificação dos alunos por letras e números.

\section{Resultados e discussões}

A pesquisa inicia-se com a observação da escola em relação: as tecnologias presentes no ambiente escolar, o espaço físico reservado à realização de aulas práticas (laboratório), o perfil dos discentes e a prática pedagógica do professor de química.

Conforme aponta o Projeto de Inovação Pedagógica da escola, o perfil do seu alunado, não é tão diferente do perfil do aluno da escola pública brasileira. Pois, na sua grande maioria, suas famílias apresentam nível socioeconômico, situando-se no patamar de 01 a 03 salários mínimos mensais, existindo considerável número de famílias que ganham menos de 01 salário mínimo por mês, ou vivem exclusivamente do Programa Bolsa Família do Governo Federal.

O fato é que a escola dispõe de um laboratório de química amplo, porém sem condições plenas da realização de atividades laboratoriais, uma vez que, parte do material disponibilizado através do Programa Alvora III, do Governo Federal, não tem reposição e encontra-se danificado. Mesmo diante das dificuldades apontadas anteriormente, para a realização da pesquisa utilizamos os recursos tecnológicos, os reagentes e vidrarias disponíveis na escola. 
Conforme mencionado na parte introdutória deste estudo, para a pesquisa foram escolhidos aleatoriamente 16 (dezesseis) alunos da $3^{\mathrm{a}}$ série do ensino médio, da turma $\mathrm{A}$, a fim de verificar se 0 uso da experimentação com o auxílio da tecnologia interativa facilita a aprendizagem dos conteúdos estudados em sala.

Segundo análises dos resultados constatados no questionário respondido pelos alunos participantes da pesquisa, confirma o que já diz a rica literatura em artigos e livros que apontam a importância da experimentação no ensino de química, como forma de comprovar os conhecimentos vistos em sala de aula.

Veja o que responderam, quando perguntado na questão 1. Você considera o experimento importante para o desenvolvimento das aulas em química?

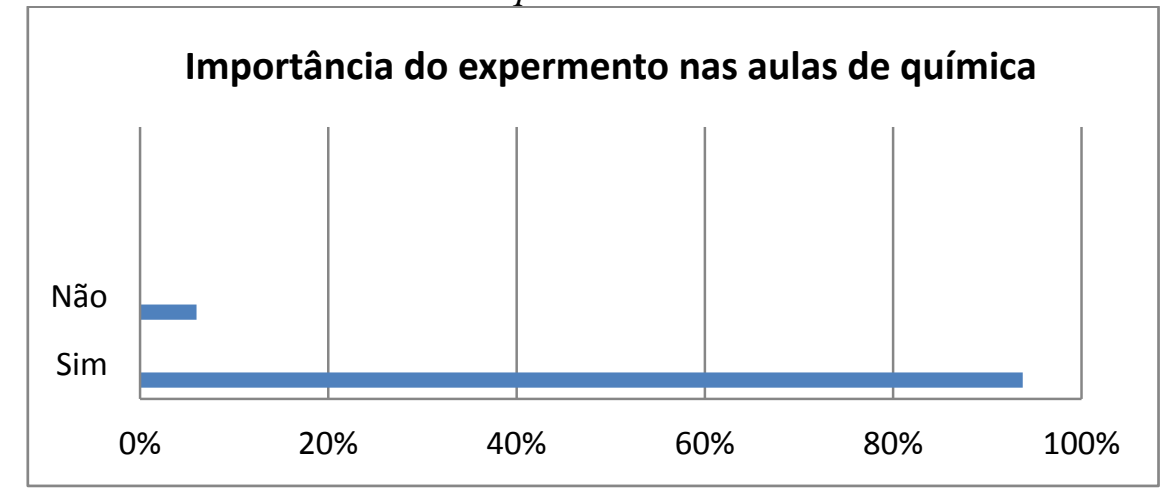

Gráfico1 - Pesquisa sobre a experimentação com auxilio da tecnologia interativa

A partir da análise deste gráfico é possível perceber que, um grande número de estudantes (94\%) acredita que as aulas de química com experimento ajudam a visualizar o que estão aprendendo, além de aprender na teoria e na prática. O prazer pelo aprender não é uma atividade que surge espontaneamente nos alunos, pois, não é uma tarefa que cumprem com satisfação.

O que observamos no gráfico 1, é que quase a totalidade dos alunos são enfáticos em afirmar que o uso de experimento, utilizado para o confronto da teoria x prática dos conteúdos é importante para facilitar o processo de ensino-aprendizagem.

Corroborando com as essa afirmação descreve Cardoso e Colinvaux (2000), para os estudantes, manusear substâncias, realizar práticas e comprovar os conhecimentos vistos em sala de aula são importantes, tornando a aprendizagem mais fácil, atraente e interessante.

Já em relação à pergunta: $O$ experimento realizado durante essa aula melhorou a forma de aprender química?

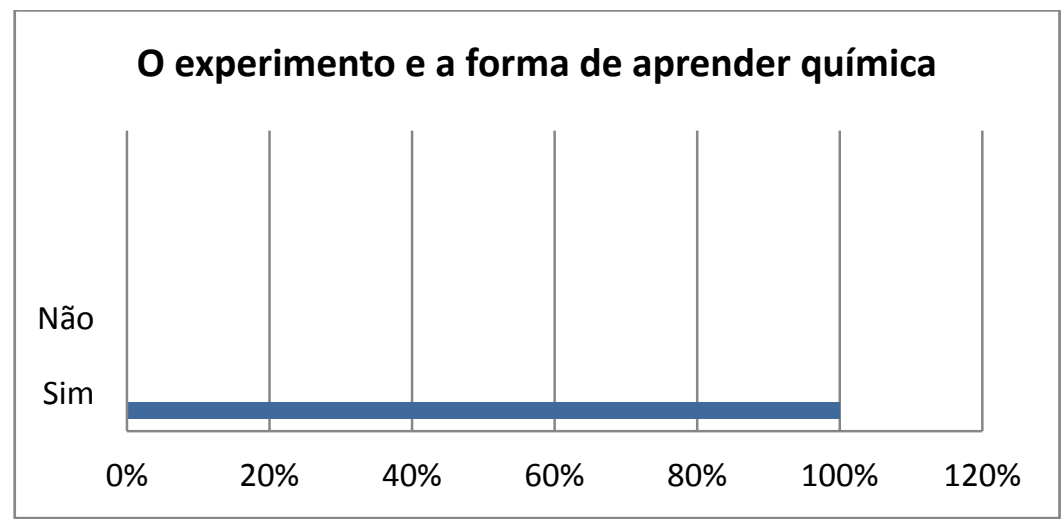

Gráfico 2 - Pesquisa sobre a experimentação com auxilio da tecnologia interativa

O resultado apontado neste estudo, extraído da questão 2 do questionário aplicados com os alunos, conforme aponta o gráfico 2, por unanimidade os alunos compreendem e são enfáticos em afirmar que o experimento realizado durante a aula prática no laboratório da escola, melhorou significativamente seu aprendizado em química. 


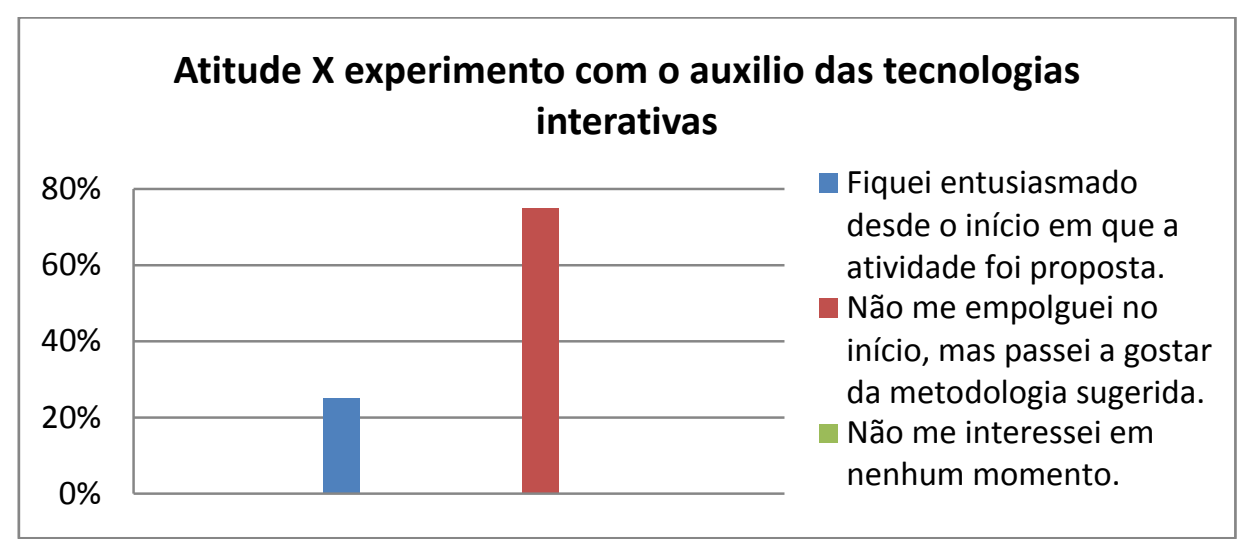

Gráfico 3 - Pesquisa sobre a experimentação com auxilio da tecnologia interativa

De acordo com as informações extraídas da questão 3 , que relaciona à atitude do aluno no tocante a metodologia da experimentação com o auxílio das tecnologias interativas, constatamos que $75 \%$ dos alunos não se empolgaram no inicio, mas que posteriormente passaram a gostar da metodologia utilizada. E os outros $25 \%$ apontam que ficaram entusiasmado desde o início em que a atividade foi proposta.

Galiazzi e Gonçalves (2004) afirmam que a relevância de estruturar uma atividade experimental que considere resultados surpreendentes, em que se inclui a estética da atividade experimental, mas que os transcenda e alcance a construção de um conhecimento mais enriquecido sobre o tema. É neste aspecto que se demonstra importância da experimentação mediada pelo uso da tecnologia interativa.

Ficando claro que a metodologia utilizada pelo professor conseguiu mobilizar os alunos para apreciação do conteúdo em análise, tanto do livro didático, como na relação com a prática de laboratório com a mediação da tecnologia interativa.

Após a aplicação destes questionamentos com todos os alunos envolvidos na pesquisa, passou-se a aferir as questões somente para o grupo 1, que participaram integralmente da pesquisa.

A primeira questão suscitada a este grupo de alunos (8), no total, foi a seguinte: $O$ uso $d a$ tecnologia interativa como meio auxiliador do ensino de química facilita a compreensão do assunto estudado em química?

E todos foram unânimes em afirmar que o seu uso facilitou o processo de aprendizagem dos mesmos, conforme mostrado no gráfico 3.

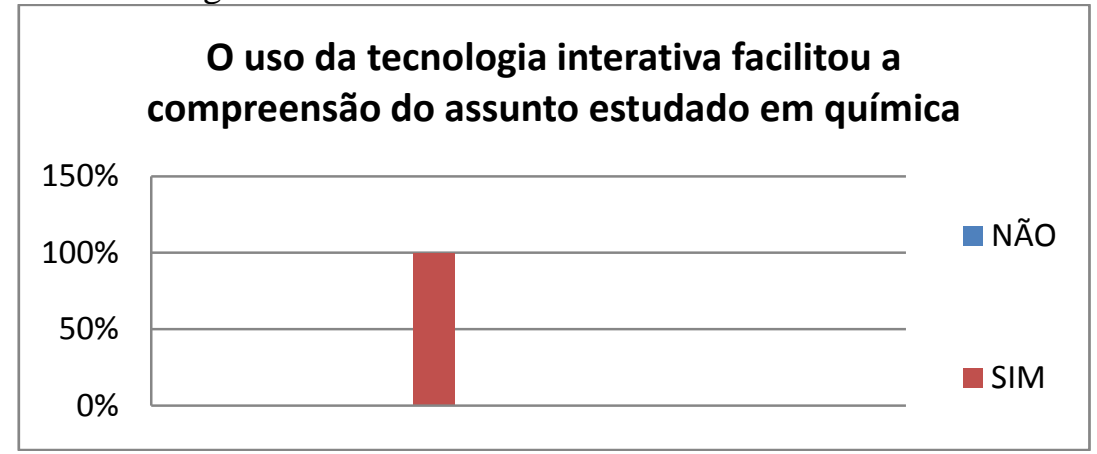

Gráfico 4 - Pesquisa sobre a experimentação com auxilio da tecnologia interativa

Conforme aponta Shuterman (1997), neste aspecto os programas interativos e os programas simuladores voltados a aperfeiçoar o processo de ensino-aprendizagem podem ajudar os alunos a transformar o modelo em seu próprio senso comum. Um grande número destes aplicativos estão no mercado para venda e muitos outros exemplos têm sido descritos recentemente na literatura. Por exemplo, o uso de um programa simulador de densidade eletrônica mostrou que este conceito, ao ser introduzido na aula teórica, foi muito melhor compreendido pelos estudantes.

Já em relação a pergunta complementar para saber a eficácia da metodologia utilizada neste estudo, solicitamos que os alunos respondessem a pergunta: Você considera o uso dessa metodologia (experimentação - gravação de vídeo - exibição - postagem) para aula de química, como? E as respostas estão apresentadas no gráfico abaixo. 


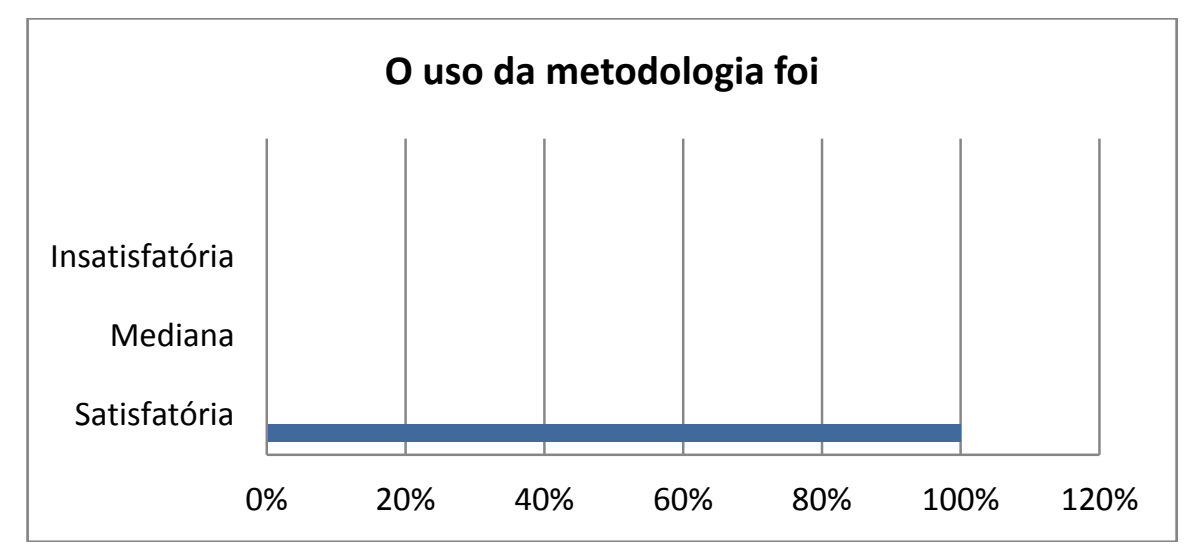

Gráfico 5 - Pesquisa sobre a experimentação com auxilio da tecnologia interativa

Pontuando algumas reflexões a cerca da análise do gráfico 5, o qual demonstra que (100\%) do aluno pesquisado, afirma que a metodologia utilizada da experimentação com gravação de vídeo e postagem na redes sociais facilitam o processo de ensino. Corroborando com essa afirmação nos reportamos a Ferreira (1998), afirmando que inicialmente toda inovação tecnológica na educação é recebida com enorme entusiasmo. E, também, Robichauxet et al (1997), fundamentalmente a Internet é um lugar para comunicação, conseguir informações, ensinar e aprender.

Seguindo a lógica da tecnologia interativa no complemento da experimentação química, os alunos responderam a pergunta: Qual sua opinião sobre a experimentação com uso da tecnologia interativa?As respostas foram mensuradas no gráfico 6 abaixo:

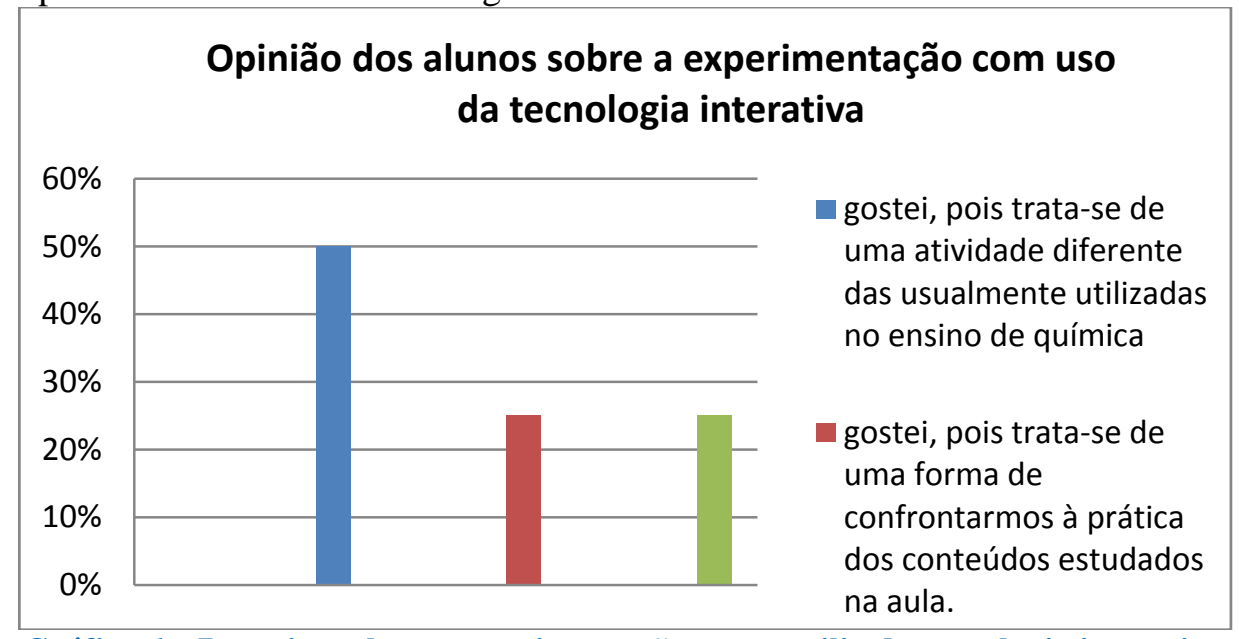

Gráfico 6 - Pesquisa sobre a experimentação com auxilio da tecnologia interativa

As respostas dos alunos em relação a experimentação mediada pelo uso das tecnologias interativas, constituiu-se o gráfico 6, e, que aponta o percentual de (50\%) deles terem gostado da metodologia devido tratar-se de uma forma de fazer com os estudantes confrontarem teoria e prática.

Nesta perspectiva, aponta Shiland (1999, p. 76), o conhecimento expresso pelos alunos na discussão de uma atividade experimental pode sempre proporcionar o início de um novo ciclo de aprendizagem, auxiliando o professor a mapear os conhecimentos do grupo sobre o tema estudado.

Já o restante, $25 \%$ (vinte cinco por cento) deles devido ser uma atividade diferente das usualmente utilizadas no ensino de química, e os $25 \%$ (vinte cinco por cento) disseram aderir a atividade devido gostarem de assistir vídeo pelo celular.

Finalizando a pesquisa todos os alunos do grupo 1 e 2 responderam uma questão aberta, onde puderam fazer uma análise sobre o conteúdo estudado durante a pesquisa. $\mathrm{E}$ o interessante é que o grupo que fez a experimentação mediada pelas tecnologias interativas argumentou o conteúdo de forma mais articulada com os conceitos e entendimento de temperatura, coeficiente de solubilidade, soluto, solvente, soluções e os aspectos matemáticos do conteúdo em questão.

\section{Considerações finais}


No seu artigo 35, inciso IV, a LDB, enfatiza que a compreensão dos fundamentos científicos e tecnológicos presentes na sociedade contemporânea devem relacionar a teoria com a prática. Tomando como base esse princípio, verifica-se que a pesquisa encontra-se fundamentada na Lei maior da educação brasileira, por ser um princípio basilar.

Assim sendo, partindo da análise dos dados, apresentamos um conjunto de características salientadas nos relatos e que precisam ser consideradas no planejamento de atividades experimentais a serem desenvolvidas no ensino de química.

Nesse sentido, argumentamos que as características emergentes da pesquisa apontam para a necessidade de discutir e enriquecer as teorias e práticas docentes sobre a experimentação, com o objetivo de superar visões simplistas que ainda pontuam essa atividade, como validação e comprovação da teoria; como elemento de mobilização; como meio de captar e formar jovens cientistas.

Salientamos ainda, a necessidade de discutir aspectos relativos ao uso adequado das tecnologias interativas, pois em recentes trabalhos publicados, em papel e/ou via eletrônica, mostraram que a informação não representa conhecimento, ou seja, acesso a informação não produz um estudante bem preparado com competências e habilidades necessária ao mundo atual.

Por outro lado, questionar os entendimentos sobre experimentação mediada pela tecnologia interativa favorece superar conhecimentos tácitos de que é um recurso que garante a motivação intrínseca dos alunos. Vai mais além, pois favorece a introdução das tecnologias ao processo educativo.

Portanto, o mais importante no uso das tecnologias interativas na experimentação é a abordagem pedagógica que o professor pode imprimir, não a tecnologia em si, e nem simplesmente a prática em si, mas todo o processo vivenciado pelo aluno, dentro da metodologia selecionada, planejada e trabalhada pelo professor.

\section{Referências bibliográficas}

ANDRADE, Maria Margarida. Introdução a Metodologia de Trabalho Cientifico. $7^{\circ}$ ed. Atlas. São Paulo: 2006.

Ministério da Educação. Diretrizes Curriculares Nacionais para o Ensino Médio. Brasília: 1998b.

Orientações curriculares do ensino médio. Brasília: 2004.

BRASIL. Lei de Diretrizes e Bases da Educação Nacional. Lei número 9394, Brasília: 1996.

Cadernos de Formação de Professores do Ensino, etapa II. UFPR/ Setor de Educação, Curitiba: 2014.

.Integração das Tecnologias na Educação/ Secretaria de Educação a Distância. Brasília: 2005.

Brasília: 2002.

Parâmetros Curriculares Nacionais + $(\mathrm{PCN}+)$ - Ciências da Natureza e suas Tecnologias.

CAETANO, Luís Miguel Dias. O software educativo na aprendizagem da matemática: um estudo de caso no $1^{\circ}$ ciclo do ensino básico. Tese (Doutorado em Educação na especialidade de Tecnologia Educativa) - Departamento de Ciências da Educação, Universidade dos Açores. 250 p: 2012

FERREIRA, Vítor F. As tecnologias interativas no ensino. Química Nova. ed 21.: 1998.

GALIAZZI, Maria do Carmo; GONÇALVES, Fabio Peres. A natureza pedagógica da experimentação: uma pesquisa na licenciatura em química. Química Nova, v. 27, n. 2: 2004. 
MAINART, D. A.; SANTOS, C. M. A importância da tecnologia no processo ensino-aprendizagem. In: CONGRESSO VIRTUAL BRASILEIRO DE ADMINISTRAÇÃO, 7, 2010. Disponível em: <http://www.convibra. com.br/upload/paper/adm/adm_1201.pdf>. Acesso em: 02 jun. 2015.

MASETTO, Marcos T. Atividades pedagógicas no cotidiano da sala de aula universitária: reflexões e sugestões práticas. In. CASTANHO, Sérgio e CASTANHO, Maria Eugênia (orgs.). Papirus, Campinas: 2001.

MORAN, J. M. Ensino e aprendizagem inovadores com tecnologias. 2000. Disponível em: $<$ http://www.eca.usp.br/moran/inov.htm>. Acesso em: 24 jul. 2015.

PERRENOUD, Philippe. O ofício de aluno e o sentido do trabalho escolar. Porto Editorial LDA. Porto: 1995.

RANCIÈRE, Jacques. O mestre ignorante. Cinco lições sobre a emancipação intelectual. Autêntica. Belo Horizonte: 2002.

ROBICHAUX, J.;Seller, J.; “QuestionAboutthe Internet in anEducation Setting”; Network WorkingGroup, 1996. ftp://ds.internic/rfc/941.txt; b) Green, D. W. FronNowOn: The EducationalTechnol. J. 1997, 6 (4), jan., http:/ /fromnowon.org/jan97/websearch.hmtl; c) Rice University, http// rice.edu/fondren/netguides/strategies.html.

RODRIGUES, Neidson. Educação: da formação humana à construção do sujeito ético. Educ. Soc. vol.22 n .76 , Campinas: 2001.

SAVIANI, Dermeval. A Nova Lei de Diretrizes e Bases. In: Pro-Posições, n. 1, p. 7- 13, Campinas: 1990.

SAVIANI, Dermeval. Pedagogia Histórico-Crítica: primeiras aproximações. Cortez; São Paulo: 2012.

SHUTERMAN, G. P.; Shuterman A. J. J. Chem Ed. 1997, 74.

SILVA, Marco. O salto para o futuro. MEC. Disponível em: http://portal.mec.gov.br/seed/arquivos/pdf/2sf.pdf. Acesso em 20 de maio de 2015.

SILVA, Anderson Jesus. Aprendizagem Cooperativa no Ensino de Química: Uma Proposta de Abordagem em Sala de Aula. In: Encontro Nacional de Pesquisa em Educação em Ciências, Florianópolis: 2009. 